\title{
Implicit Deductive Responding in Humans
}

M. Siemann and J. D. Delius

\begin{abstract}
Allgemeine Psychologie, Fachgruppe Psychologie der Universität,
\end{abstract} D-78464 Konstanz

Cognitive competences are traditionally considered to be dependent on consciously accessible, language-based mind processes. The understanding of human cognition has been advanced mainly by requiring subjects to report on experienced events and processes verbally. There is, however, recent evidence that humans are also capable of complex perceptual and mnemonic feats without necessarily being aware of it [1].

The implicit/explicit dichotomy may also apply to cogitation, but up to now research has involved complex tasks that are not particularly suited for precise analysis [2]. We have therefore turned to a simply structured deduction problem, a transitive inference task. Such problems are conventionally presented in a verbal form, e.g., "Anna is taller than Betty; Carol is smaller than Betty; who is taller, Carol or Anna?". But inspired by Piaget [3], several workers have striven to develop increasingly nonverbal versions of the problem [4]. We have employed a modification of a procedure that has been successfully used to study transitive inference in animals [5]

Twenty-four subjects (12 female, 12 male, mean age 23) participated in the experiment. Six polygons of different shapes but equivalent complexity designated here as A, B, C, D, E, and F, served as stimuli (Fig. 1a). Presented in overlapping pairs they conveyed the premises. Half of the subjects received the pairs $\mathrm{A}+\mathrm{B}-, \mathrm{B}+\mathrm{C}-, \mathrm{C}+\mathrm{D}-$, $\mathrm{D}+\mathrm{E}-$, and $\mathrm{E}+\mathrm{F}-$ ("+" denoting rewarded, "-" punished stimuli), based on an underlying transitive sequence $\mathrm{A} \rightarrow \mathrm{B} \rightarrow \mathrm{C} \rightarrow \mathrm{D} \rightarrow \mathrm{E} \rightarrow \mathrm{F}$. The other half received the pairs $\mathrm{F}+\mathrm{E}-, \mathrm{E}+\mathrm{D}-$, $\mathrm{D}+\mathrm{C}-, \mathrm{C}+\mathrm{B}-$, and $\mathrm{B}+\mathrm{A}-$ based on the reverse sequence. Since the two groups yielded identical results a unified At to F- terminology is used henceforth.

The experiment was run as a singlesession computer game, the subjects not 
being told about the true nature of the task. They led a cartoon figure through a fantasy castle, successively choosing between two doors bearing one of the stimulus pairs listed above by pressing either a left or a right key. The door allocation of the positive and negative stimuli was random. When the subject chose a positive door, the figure was admitted into a treasure chamber and earned a coin that added to his hoard. When be chose a negative door the figure entered an alley where he had to give a coin to a beggar. The subject initiated the next trial by pressing a middle key.

Each of the five stimulus pairs was presented equally often. To facilitate acquisition they initially occurred in randomly ordered runs of eight (until the 80 th trial), then of four (until the 160th trial), and lastly of two same-pair trials. From the 241st trial onwards the individual pairs were randomly sequenced. A chance sixth of the trials with each pair was now not reinforced, leading the figure to an empty passage. This was a preparation for later, feedback-free test trials. The subjects required between 300 and 840 trials (mean 395 trials) to reach a preset learning criterion of at least $70 \%$ correct choices on every training pair within a block of 60 consecutive trials. During the subsequent test phase, the novel pairs $\mathrm{BD}, \mathrm{CE}$, and $\mathrm{BE}$ were each presented ten times in unreinforced trials that were randomly interspersed among 100 learning trials presented as

a
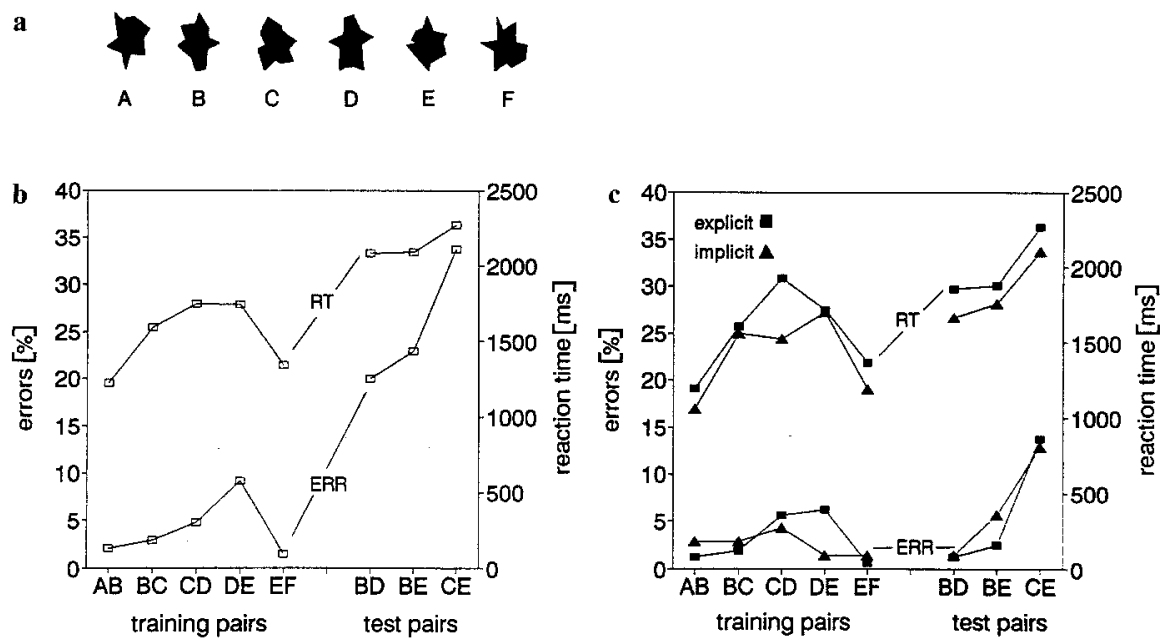

Fig. 1. a) Stimuli employed, b) error rates ( $E R R)$ and mean reaction times $(R T)$ for training and test pairs during test phase averaged over all 24 subjects, c) mean error rates and mean reaction times for training and test pairs during test phase for a group of 7 subjects who solved the test task implicitly and for a group of 8 subjects who did so explicitly. There are no significant differences between the performances of explicit and implicit solvers (U-tests, $p s>0.05$ ) ized the stimulus relationships and used this knowledge to solve the test pairs. The seven other solvers, however, definitely did not know what the computer game was about. These subjects declared that they had either gambled, guessed, or responded according to strategies that were de facto wrong or that they could not explain. Nevertheless, this group was not worse in accuracy or speed on test and learning pairs than the other group comprising the eight subjects who were evidently aware of the experiment's purpose and their own strategies (Fig. 1c). When confronted with the card-laying task, the unaware subjects were at first baffled by it and some insisted that they could not do it, but when pressed, five of them eventually guessed the correct order. During debriefing, the unaware subjects regularly expressed surprise about the serial structure they had not recognized. Incidentally, of the nine nonsolvers only one recognized the nature of the task and none succeeded with the card-laying task.

The result worth emphasizing is that almost half $(46.7 \%)$ of the subjects who responded transitively at much better than chance level were completely unable to report verbally how they had achieved such excellent performance. This demonstrates that humans can behave according to deductive rules implicitly without being consciously aware of them. The fact that five of the seven relevant subjects could transfer their implicit knowledge to the cardarranging task shows that they nonetheless learned something more than a simple instrumental skill. It is also remarkable that their objective performance did not differ in any way from that of subjects who had explicit cognition of the task. This suggests that the latter might also have primarily responded according to implicit procedures.

It seems possible that the algorithm used by all solvers may rely on the graded weights that the different stimuli can accumulate during acquisition according to basic conditioning principles. Several mathematical models [6] embodying elementary learning mechanisms of this kind have been found to simulate the transitive inference-like performance of pigeons, squirrel monkeys, and chimpanzees [5] fairly accurately. Stimulations with one of the models, the socalled Luce algorithm, show that such a mechanism can also emulate the present 
results. The model specifies that the rewarded or punished choice of stimulus $x$ on trial $i$ leads, respectively, to a stimulus value increase $\left(V_{\mathrm{x}, \mathrm{i}}=V_{\mathrm{x}, \mathrm{i}-1}+V_{\mathrm{x}, \mathrm{i}-1} * \beta\right)$ or decrease $\left(V_{\mathrm{x}, 1}=V_{\mathrm{x}, \mathrm{i}-1}-V_{\mathrm{x}, \mathrm{i}-1} * \gamma\right)$ and that the probability of choosing stimulus $x$ rather than $y$ on trial $i+1$ is given by $p_{\mathrm{xy}, \mathrm{i}+\mathrm{l}}=V_{\mathrm{x}, \mathrm{i}} /\left(V_{\mathrm{x}, \mathrm{i}}+\mathrm{V}_{\mathrm{y}, \mathrm{i}}\right)$. Inserting $\beta=$ $0.06, \gamma=0.60$, training for 500 trials, and averaging results over the last 100 trials yielded the following error rates: training pairs AB: $1.7 \%, \mathrm{~B}: 3.4 \%$, CD: $4.9 \%$, DE: $7.5 \%$, and $\mathrm{EF}: 1.4 \%$; test pairs $\mathrm{BE}: 0.1 \%, \mathrm{BD}: 0.2 \%$, and $\mathrm{CE}$ : $0.4 \%$. They reproduce the performance of solvers shown in Fig. 1c reasonably well (more complex model variants that yield even better fits are considered in [7]). This suggests that at least those humans who solve non verbal tasks implicitly, but perhaps even those who apparently do so explicitly, may be behaving transitively without recourse to the propositional rules of classical logic.

These circumstances suggest that an implicit transitive inference competence may be an evolutionarily ancient trait. Indeed, there are field data indicating that transitivity competences may promote biological fitness in several avian and mammalian species, particularly in the context of coping with social hierarchies [8].

The research was supported by the Deutsche Forschungsgemeinschaft. We thank Prof. C. D. L. Wynne (Perth) for advice, Profs. J. Emmerton (Purdue), E. Scheerer (Oldenburg), R. Ulrich (Kon$\operatorname{stanz}$ ), and Dr. L. von Fersen (Kon$\operatorname{stanz}$ ) for comments, Dr. J. Delius (Berlin) for checking the English, and A. Niemuth for typing.

1. De Haan, E. H. F., Young, A., Newcombe, F.: Cogn. Neuropsych. 4, 385 (1987); Pöppel, E., in: Encyclopedia of Neuroscience (G. Adelman, ed.). Boston: Birkhäuser 1987; Reber, A.: J. Exp. Psychol.: Gen. 118, 219 (1989); Schacter, D. L.: J. Exp. Psychol.: Learn. Mem. Cogn. 13, 501 (1987)
2. Cohen, N. J., in: The Neuropsychology of Memory (L. R. Squire, N. Butters, eds.). New York: Guilford 1984; Berry, D. C.: Quart. J. Exp. Psychol. 43A, 881 (1991)

3. Piaget, J.: Arch. Psychol. 1921, 141

4. Bryant, P. E., Trabasso, T.: Nature 232, 456 (1971); Breslow, L.: Psych. Bull. 89, 325 (1981); Chalmers, M., McGonigle, B.: J. Exp. Child Psychol. 37, 355 (1984)

5. McGonigle, B., Chalmers, M.: Nature 267, 694 (1977); Gillan, D. J.: J. Exp. Psychol:: Anim. Behav. Proc. 7, 150 (1981); Fersen, L. von, Wynne, C. D. L., Delius, J. D., Staddon, J. E. R.: Naturwissenschaften 77, 548 (1990)

6. Fersen, L. von, Wynne, C. D. L. Delius, J. D., Staddon, J. E. R.: J. Exp. Psychol.: Anim. Behav. Proc. 17, 334 (1991); Couvillon, P. A., Bitterman, M. E.: ibid. 18, 308 (1992); Wynne, C. D. L., Fersen, L. von, Staddon, J. E. R.: ibid. 18, 313 (1992)

7. Werner, U. B., Köppl, U., Delius, J. D.: Z. Exp. Angew. Psychol. 39, 662 (1993); Siemann, M.: Ph. D. thesis Univ. Konstanz 1993

8. Fersen, L. von, Delius, J. D.: Spektr. Wissen. 1992 (Jul.), 18 